lglisson@bmcc.cuny.edu

Shane McConnell, BOROUGH OF MANHATTAN COMMUNITY COLLEGE, smcconnell@bmcc.cuny.edu

Mahatapa Palit, BOROUGH OF MANHATTAN COMMUNITY COLLEGE, mpalit@bmcc.cuny.edu Jason Schneiderman, BOROUGH OF MANHATTAN COMMUNITY COLLEGE, jschneiderman@bmcc.cuny.edu Cynthia Wiseman, BOROUGH OF MANHATTAN COMMUNITY COLLEGE, cwiseman@bmcc.cuny.edu Lyle Yorks, TEACHERS COLLEGE, COLUMBIA UNIVERSITY, yorks@exchange.tc.columbia.edu

\title{
Looking in the Mirror of Inquiry: Knowledge in Our Students and in Ourselves
}

\section{ABSTRACT}

At a large, urban community college located in the Northeastern United States, a group of faculty interested in helping students assume agency in their own learning used the methodology of Collaborative Inquiry $(\mathrm{Cl})$ as a way to examine the factors that help or hinder this process. Unexpected was the epistemological shift they underwent as a result of the $\mathrm{Cl}$ process. The group had hoped to find ways to make students less passive, starting with the question "How do we make students into makers of knowledge?" The $\mathrm{Cl}$ methodology, however, required the faculty to examine themselves and their own relationship with the process of knowledge-making. Through the inquiry process, which required participants to question their own assumptions, they realized that, even though they considered themselves makers of knowledge within their respective fields, they had approached this knowledge-making process quite passively. The group members thus found themselves involved in a Collaborative Inquiry process that they hadn't initially fully understood but which required that they become active makers of knowledge. As a result, members rejected many of the assumptions implicit in the original question and began to approach the challenge of teaching and learning more actively, more respectfully, and with more humility. This article offers a narrative of this group's process, the conclusions they reached, a set of reflections, and considerations that others using the $\mathrm{Cl}$ process for professional development oriented inquiries may find useful.

\section{KEYWORDS}

collaborative inquiry, second person inquiry, action research, experiential learning, transformative learning 
This paper discusses the epistemological shift that a group of faculty in a large, urban community college experienced through an emergent process of Collaborative Inquiry (CI) in which we began with the question: "How can we help students become knowledge makers?" This fundamental epistemological shift in understanding how we were in relationship with our students was foundational. Specifically, this shift was one of going from agent (teacher) acting on the object (student) with the question: "How can we make our students into knowledge-makers?" to agent (teacher) understanding him/herself in relationship with the fellow agent (student). This shifted our focus to questioning how we ourselves might need to change in order to facilitate the possibility of students realizing they can be their own knowledge makers. The basis for this shift was insight into how we, as members of the institutional setting in which we worked, were more similar to our students than we would have ever thought. This unexpected, epistemological insight was an impactful change in the frame of reference through which we came to reflect on our teaching. Our focus here is to examine the process that led to this shift and the meaning that we have made of it.

Imagine for a moment that you are a graduate student in a course exploring the pedagogical dynamics of transformative learning. The course was designed for small groups to inquire and take action on pedagogical challenges through a prescribed approach. Once the group had identified a common challenge and attempted to implement the methodology that would transform their learners' understanding of a subject, you get the uneasy feeling of the group "treading water" and not making progress. Transformation is at a stalemate. The group cannot produce the final project. Different group members are coming from different disciplines and different perspectives and stubbornly refuse to see another perspective in this transformative action group.

What is your response to this story? The ending to this story is that we-the faculty co-authors of this article-are those students. We entered into a CI group at the behest of a respected and liked colleague, only to find ourselves foundering in a process we found difficult to master. Our original goal was to study our students, and to determine why they often seemed so passive in the face of new knowledge. What we found was that we exhibited many of the behaviors we attributed to our students. The process of CI led us to critically reflect on ourselves and how we interact with each other. Through painful revelations and contentious meetings, we ultimately found that our assumptions about students and the process of learning was holding us back from becoming better facilitators of our students' learning. When we let ourselves see that we shared the problems we typically attribute to the students, we were able to grow as educators and begin exploring how we might change our practices for the better. Our focus in this paper is on how the experience of CI facilitated this growth.

We begin with an introduction of $\mathrm{CI}$ and its underlying premises. Next we describe how the process unfolded in a very emergent and organic way out of a series of faculty development workshops. The Collaborative Inquiry that evolved from these workshops was pursued by a group of seven members from five disciplines: Developmental Studies, English Literature, Business, Library Science, and Adult Learning. The group embraced the spirit of CI, struggling with the challenges of engaging in inquiry, trusting that a new focus would emerge.

This narrative is important to understanding how the commitment to inquiry leads to epistemological shift resulting in critical self-reflection. While the experience can be 
looked at through a number of lenses, it is the experience of Collaborative Inquiry that is central to this paper. We end the paper with five key lessons learned.

\section{UNDERSTANDING COLLABORATIVE INQUIRY}

Collaborative Inquiry (CI) is a process through which a generative space for learning through experience is constructed by a group of collaborating inquirers brought together by a shared, compelling question (Bray, Lee, Smith, \& Yorks, 2000; Yorks \& Kasl, 2002). Through engaging in multiple cycles of reflection and action around their question the group strives to generate new insights, meaning, and knowledge. Typically, CI questions involve issues that are professionally developmental and socially controversial. These inquiries may also involve bridging social gaps and healing personal traumas. As the process unfolds, the inquirers engage each other in dialogue, test their assumptions, and make meaning of their experiences.

Collaborative Inquiry is one of a family of action research methodologies (e.g., Greenwood \& Levin, 2007; Coghlan \& Brannick, 2005; Reason \& Bradbury, 2008), and rests on the principles of holistic learning and mutual decision-making (Heron, 1996; Heron \& Reason, 2001; 2008; Reason, 1988) that define the umbrella category of "Co-operative Inquiry." The term "Collaborative Inquiry" was adopted to indicate a more inclusive and general approach, as distinguished from the narrower set of procedures that define Cooperative Inquiry (Bray et al., 2000; Yorks \& Kasl, 2002). While there are some distinctions between the two approaches, those discussions are beyond the scope of this paper. We see both methodologies as being highly similar in terms of values, underlying theory, guiding principles, and epistemological approach. We use "Collaborative Inquiry" or "CI" to describe our own process.

Among the core values and principles of $\mathrm{CI}$ is the premise that, within the inquiry process, power and responsibility are shared equally. Each inquirer is fully involved in all decisions that shape the inquiry and how it is conducted. Additionally, each inquirer actively engages in making meaning from personal experience. A range of reflective inquiry practices are utilized to surface experience, including presentational ways of knowing as well as propositional knowing.

Presentational knowing is evident in one's intuitive grasp of significance of patterns of experience and expressed in graphic, moving, poetic, expressive art forms, and story. Heron and Reason (2008) characterize presentational knowing as follows: "[it] is made manifest in images which articulate" and shape what is "inchoate into a communicable form ... expressed non-discursively through visual arts, music, dance and movement, and discursively, in poetry, drama” and telling stories (pp. 370-371). Such expression can create an empathic connection with the experience of others (Yorks \& Kasl, 2002; 2006). Presentational knowing can bridge subconscious intuitive feeling and propositional knowing by giving expression to felt awareness for reflection and articulation in terms of conceptual meaning (Kasl \& Yorks, 2012). In contrast, propositional knowing is expressed in intellectual statements conforming to the laws of logic, both verbal and numerical.

These values and principles are grounded in the epistemological stance of doing research with rather than on people (Heron \& Reason, 2001). A core principle of CI is that learning involves changing not just the system they are working with, such as a class, group, function, organization, or community, but the learners themselves, as they come to realizations about their relationships with the dilemma or challenge that has drawn 
these inquirers together. The underlying purpose of CI is for the inquirers to change themselves in how they interact with the system in which they are embedded. Yorks and Kasl (2002) illustrate this principle as distinct from the focus of much action research. The authors note:

a typical action research question might be posed by a group of educational administrators as, "How can we improve the way that teachers use technology in the classroom?" A CI question posed by this same group of administrators might be, "How can we improve our ability as administrators to influence the way teachers use technology in the classroom?" The focus of the action research question is on changing the system directly, whereas the CI question focuses on the inquirers themselves as the primary target for learning and change. (p. 5)

While the inquirers cognitively understand the principle articulated above, the felt experience of it only emerges through the inquiry process itself. For example, as part of an inquiry that was part of the Leaders for a Changing World initiative at the Research Center for Leadership in Action in the Wagner School at NYU, a group of community organizers came together with the shared concern that their organizing actions alone were not enough to sustain their action initiatives (Kovari et al., 2005). They initiated their CI around the question, "How can we teach people to be more strategic, conceptual, and creative in their thinking?" (Kovari et al., 2005). As their inquiry evolved, they came to realize that the problem wasn't "teaching," but how they conceived of their relationships to people in social action events. They came to realize that "strategic thinking is what happens between us" (p. 11). This realization is described in a comment by a member of our inquiry group that "People always say to us organizers 'Tell me what to do,' and we say, 'Do this.' We do all the strategic and creative thinking and wonder why they aren't thinking strategically." The CI participants came to understand they needed to change how they were in relationship to the people and groups with which they were working. This kind of personal insight and awareness also emerged in the inquiry described in this paper. While these examples seem straightforward, the experience of shifting one's frame of reference-one that is embedded in a habit of mind and in one's existing interpretation of his or her experience-can be challenging. In the words of Peter Reason (1992), "Good inquiry will only take place if it is disturbing in some way. A measure of a valid inquiry is if it changes the inquirers" (n.p.).

Many Collaborative Inquiries are initiated in a relatively systematic way, within the context of an institutional initiative, such as the Leaders for a Changing World program referred to above, or as a dissertation project (e.g., Bray et al., 2000; Mankey, 2007). In response to a sense of personal discomfort or dilemma, an individual or group invites others to engage in an inquiry into the issue. Collectively, the inquirers frame the issue in terms of a question that can be answered through examining 'data' derived from their personal experiences. They go through the process of forming the group through creating the question and agreeing on the scope of the inquiry, creating the conditions for group learning. The group sets norms, agrees on learning practices, and decides how they are going to capture data. They then move on to cycles of reflection and action, with the goal of making meaning from their ongoing experiences. Our CI was more emergent and or- 
ganic. We journeyed from a faculty development workshop to fundamentally transforming our relationships to our students and each other.

\section{FROM WORKSHOPS TO INQUIRY: UNDERTAKING CI AT A COLLEGE}

\section{Framing our inquiry}

The CI began with the shared recognition that students did not take agency for their learning. There was consensus that students expected knowledge to be 'given' to them. Participants shared anecdotes at an early meeting. Typical stories included the student who simply wanted writing center tutors to tell her what to write, and students who began inquiries to the research librarian with: "I don't know what my professor wants," or "I'm sorry to bother you." Two things become clear from these anecdotes. First, the students see their assignments as having no personal connection to their own lives; they are merely something required in order to pass a course. Second, the students do not think their questions are important enough to merit attention. We were frustrated that students expected to have ready answers to their research questions, rather than recognizing the need to synthesize information to find their own answers.

In one of these sessions, a participant articulated his question like this: "Why is it that students have a hard time in seeing themselves as makers of knowledge?" The question resonated with all of us - we wanted our students to be active learners who take responsibility for their learning. Everyone in the room wanted students to identify as makers of knowledge-this was precisely our goal for them in college.

As mentioned above as we transitioned to the CI, our group was inter-disciplinary, with seven members coming from Developmental Studies, English Literature, Business, Library Science, and Adult Learning. All of us had graduate degrees; we were "experts" in our fields. We saw ourselves as "knowledge-makers" and believed that we had to train our students to develop the same cognitive processes and the same sense of agency that we had. We assumed that anybody could acquire knowledge, if they set their minds to it-even in new fields. And we had confidence that learning was not a difficult enterprise. We had been doing it for so long-from kindergarten, in fact. We simply had to pass on that same confidence to our students. Our facilitator, with previous experience in leading CI inquiries, served as a guide to help us articulate the inquiry question and then use the CI process to find an answer. Working within the paradigm of CI practice, which tries to get away from the subject and object reference points that are dominant in academic research, we carefully reworded our question: "How can students become knowledge makers?" By knowledge making, we meant having a sense of engagement, self-direction, and responsibility for their own learning.

In subsequent meetings, the group circled around this question. Through this process of inquiry, we encountered several obstacles beyond the expected differences in approach shaped by discipline and training. Curiously enough, it became apparent that, before we could help students become knowledge makers and develop agency, we ourselves had to work through psychological and intellectual barriers that inhibit cognitive and emotional growth.

Almost a year passed as we met in groups every four to five weeks. Our facilitator played the role of a participant-observer. We often expected him to chair the meeting, 
and he finally had to explain that he was not there to facilitate the group in a traditional sense. Facilitating a CI is different from traditional group facilitation. There is not a focus on actively intervening to maintain agreed upon group norms, while the actors engage with the group's content agenda. As the Research Center for Leadership in Action defines inquiry, the facilitator allows the dynamics of the group to emerge and then encourages the participants to reflect on and share their often unspoken thoughts about what happens and how they might effectively move forward. Process and content are both part of the inquiry. $\mathrm{CI}$ is based on whole person learning and connecting and sharing feeling and emotion brings into the conscious dialogue underlying realizations (Heron \& Reason, 2008; Yorks \& Kasl, 2002). The facilitator's role was not to keep the group out of trouble but to help us get out of the trouble we found ourselves in. As our facilitator explained, CI is a full inquiry by all participants in the group. To be a full inquirer, one has to be able to take action on the emerging dynamics among the participants as they inquire into their question. However, he did suggest that we develop a structured agenda for each session.

Although imposing a structure in Collaborative Inquiry may feel artificial initially, it may ultimately be freeing. Our facilitator suggested several practices. One was that we begin each meeting by first sharing our experiences in terms of actions taken since the last meeting. We looked at where we were, what we had tried out since the last meeting, and different approaches we thought we could use (Brookfield, 1980). Another practice was using a drawing or a metaphor exercise to explain our emotional and cognitive orientation at the start of the meeting. Finally, we would simply begin discussion until the sharing process concluded. The goal was to get divergent experiences on the table, prior to making meaning and seeking convergence.

\section{Planning the conference}

One of us suggested using a presentation at an upcoming conference to add some urgency and structure to the process. At the next CI meeting, we looked at the call for papers and began to put together our proposal. To many of us, that meeting felt like progress. We had a clear task to accomplish, and we had completed it by the end of the meeting. The research design and sub-group questions were quickly outlined, with those who were more assertive speaking loudest. A number of the faculty involved brought their outside projects to the proposal and began to connect CI to other work that they were doing with students. Even though many of us left the room feeling that we were finally on track - we had met a deadline, and now we had another deadline to meet - this meeting precipitated the crisis that brought us together in the moment that we all agree was the beginning of a truly Collaborative Inquiry.

Shortly after the meeting, one of the key members abruptly withdrew from the CI group. She made it clear that she had felt ignored during the session in which we had written the proposal. Where most of us had felt a sense of community and collaboration, she had experienced a sense of isolation and disrespect. The remaining group turned inward in response to her departure. At this moment, we had to carefully examine our dynamic. None of us wanted to go back to having no structure, nor did we want to continue with the same structure. After one or two meetings in which we mostly strategized about how best to apologize to our colleague and bring her back on board, we felt compelled to share our emotional responses with each other as a part of our personal process. Out of this experience of inner turmoil, we developed a sense of trust that started us on our journey 
into the actual inquiry process. We all eventually realized that we could not alter our colleague's decision to leave. Respecting her decision to leave was an important part of the CI process. It also contributed to our learning. In the words of one of our colleagues in the group, "While her departure was disconcerting, it definitely made us more acutely aware of our interactions not only within the group, but also in the wider academic community. It also affected my view of how I interacted with people on a personal basis."

It was easy to have circular conversations that simply aired the same complaints about how our students have difficulty working in groups. How would we discuss our own difficulties with the same task? This experience had been something of a disorienting dilemma (Mezirow, 1991) for us that moved us into a new phase of the inquiry process, one in which we began a process of more deeply focusing on how we were contributing to the student behavior we wished to change, at least in part, through our own actions. Changing the context would require a change on our part. This was a new focus for us, one very different from the more instrumental discussions often characterizing faculty committees and project teams. As will be discussed in the next section of the paper, this too was an emerging journey.

\section{A new focus}

We now began to focus on the question of how Collaborative Inquiry was different from other types of inquiry. Our facilitator provided articles and an explanation of CI that demanded we develop the level of self-awareness required. It became clear that we would have to change ourselves in order to grow.

As a group, we became more focused on the need for a new dynamic. This reinforced what we intuitively knew: in order to proceed, we needed to inquire into the interactions among ourselves. We could not make knowledge in our group unless we dealt with our own emotional barriers - all the baggage that each of us brought to the table in our interactions in the group, with colleagues and in the culture of the larger institution.

Three topics dominated our conversations: 1 ) our presentation at the conference; 2 ) working with our students; and 3) our interpersonal dynamics. All of these areas were in constant flux, and we had no clear idea of how to move forward. At a particularly contentious meeting, our facilitator intervened for the first time. He suggested a structure for the group meetings. He suggested that, instead of having free ranging discussions with no beginning and end, it would be a good idea for each person to pilot new techniques in the classroom and then come back to report. Furthermore, when one person was reporting what was happening in their classroom, the others would not jump in to explain the cause of the student behavior, but would simply listen until the person was done. They could ask questions at the end of the presentation, which the speaker would note, but would not be compelled to answer right away. This process would enable reflection. We also decided that we would no longer discuss our colleague's departure, and that we would separate our discussions of the conference from discussions of work with our students. The group heaved a sigh of relief at getting some type of structure.

Our facilitator could not attend the next session. Nevertheless, the group followed the structure. One of us led an exercise in which one-by-one, we listed our assumptions regarding student knowledge and then explained how we would change our pedagogy if those assumptions turned out to be wrong. Then, other group members asked us questions about those assumptions. Structuring this challenge into the group dynamic elimi- 
nated resistance to more open modes of thinking and led members of the group away from simply reiterating familiar ideas to challenging those assumed beliefs. The process seemed to go very well. This was our last meeting in Spring 2012 and we closed the semester with a sigh of relief.

As we moved forward, we tried to bring the collaboration into our classrooms. One group member asked another to present a gamified lesson he had developed for helping students develop a thesis for a research project. We, thus, expanded our relationships beyond the group to include interaction with students (and each other's students). Personal interactions were vital in building relationships. Without these interactions, the relationship would not have evolved or developed. Without interpersonal interactions there is no affective glue to construct and cohere the relationship with another person.

\section{A new practice}

After more than a year of the CI process, we found our interactions with our students and colleagues changing. One of us began to see her work quite differently:

These reflections followed me back to the library, where they informed the way that I worked with my colleagues. Frequently, the issues discussed in CI were mirrored in the wider world. At the time, I was teaching a large number of library instruction classes for professors in various academic departments. My practice had evolved from a basic lecture to something more like a conversation between the students, the professor, and myself. I found that the more I could engage the students in the decision-making process, the more successful the class became. It was important to get across the idea that research is about the student's own development as a scholar, a worker, and a complete person; it was not just an assignment that the student was compelled to do. I asked a lot of questions, rather than telling them what I wanted them to learn and tried to help them come up with their own conclusions. Many of the American students had gone to inner city high schools in which the main task of a "good" student was to stay seated and not make trouble. My role was to let them know that it was fine to have their own opinions and take direct responsibility for their education. Surprisingly, that process occasionally brought fairly emotional reactions from students that I helped. Often the speech topics they chose were based on real issues that they had experienced in their own lives: stop and frisk, bullying, illnesses of family members, family violence, and in the case of international students, the sometimes troubled history of their home countries. The techniques discussed in the CI articles and in our group conversations helped me reflect on how I could engage with students on a more equal footing. I discovered that when I found ways to let the students know that their knowledge and life experience was of equal value to mine and listened carefully to what they had to say, a "field of empathetic connection" (Yorks \&" Kasl, 2002, p. 185) could occur. The oil that facilitated that connection was most commonly humorous remarks that lightened the tone of the conversation. That prepared the students to open up to the more technical aspects of narrowing down their topic and finding credible research sources 
Another member of the group recounts his transformation to seeing students as fellow agents:

Recently, I was teaching a vocabulary lesson in class, and after explaining that the words 'moral' and 'immoral' are antonyms, a student asked if 'amoral' was synonymous with 'immoral.' I asserted that they meant approximately the same thing. The student then corrected me, explaining that she looked the words up the night before, and read the definitions aloud. Other students laughed, as they witnessed the teacher being one upped. I considered it an opportunity to be embarrassed but instead explained that I did not know the precise meanings of every word. Instead, I wrestle with meanings and used the context clues as my ally to figure out what words mean or at least make a best guess. I further pointed out that my students could use the same strategy when they face the final exam in reading. They will not need to know every word in every passage because I'm teaching them skills that they can use to work on challenging texts. If my students feel empowered by one upping their professor, my ego need not get in the way. My student felt inspired to engage in knowledge making on her terms and her contribution has a place. I found it invaluable to walk into the classroom with the same vulnerability that was promoted by the CI group. Putting my mask of perfection on before I enter the classroom cannot possibly help my students, and a superior attitude takes away from knowledge making.

In order to help students take an active part in their learning process, we had to take a close look at how we engaged with each other, including our own behavior and mode of communication. It would be crucial to cultivate sensitivity to the perspective of others. While it is not hard to understand these concepts intellectually, it is much more challenging to practice the awareness necessary to put them to work. At one meeting, one of us described this learning process as "two steps forward, and one step back."

A significant barrier to the inquiry process was our interpersonal communication style. We would often intercede when colleagues expressed their concerns about what happened in their classroom, advising them on how to set it right. This made the participants feel that they were being judged and made them feel extremely vulnerable. It directed the conversation away from inquiry. CI involves three simultaneous levels of inquiry: first person inquiry (awareness of one's intentions, strategies, and sensed performance); second person inquiry (building inquiry into one's interactions with others through mindful use of speech); and third person or system level inquiry (awareness of the larger system in which one is engaged, be it a team, department or institution). Torbert and Taylor (2008) emphasize that speaking-and-listening-to-others is integral to learning in second-person inquiry. Mindful use of speech involves framing one's intentions before advocating, illustrating with descriptive examples one's advocated points, and then inquiring into others thoughts and experiences with open-ended questions. When built into the conversation as a way of engaging with others, this mindful speech pattern enabled us to develop a shared mental model, helping us to articulate our assumptions and keeping communication on track. Torbert and Taylor (2008) further advocate that those engaging in second-person inquiry practice these different patterns of speech to 
gradually transform conversations from habitual repetitive conversations to dialogues. Over the course of the CI process, we developed this mindful use of speech pattern. However, since this type of communication style requires a high level of self-awareness and practice, we often found ourselves going back to our old mode of habitual conversation style, which led to conflict.

These changes in behavior and attitude may seem like easy alterations, but these were not easy adjustments at all. Only by going through the difficult work of self-examination and constantly working to implement these habits of thinking and speech were we able to make changes. We had to surrender our attachment to our own expertise; we had to stop telling each other what to do and how to be. The impulse to impose our own solutions on others makes us think that transformation is easy-for other people. In practice, transformation is difficult because it cannot be imposed.

Discussing the CI process at a conference seemed to illustrate this 'empathetic connection' to a student who was sitting in on our presentation. After listening to the discussion of our process, our conflict resolution, and our change in direction, the student remarked during the question and answer session that she found it relieving to see professors having to work through conflict because it meant that students were not alone in having to deal with conflict and doubt when communicating with peers inside and outside of the classroom. It might be that to students, a conflict could threaten to reveal weakness, whether it pertains to communication or awareness or confidence. For the student, it seemed to be reassuring that faculty were willing to get their hands dirty. It made her feel better about the process she underwent by participating in academia at the student level. She benefited from hearing of our work because she could relate to our difficulties and vicariously share the experience. Essentially, we took off our masks, and when she saw us, she saw herself, which was empowering.

The awareness of the importance of relationship building with each other and our students had changed the way we structured our pedagogy. We had addressed our own dynamics, and found that in doing so, we were able to return to our initial object of inquiry. The group had passed through several stages in the Collaborative Inquiry process: Establishing professional/disciplinary perspectives/stance; reckoning with vulnerability and trust issues; understanding $\mathrm{CI}$ and establishing a structure for our inquiry; embracing the need for structure, becoming less task-oriented; and accepting each other and where we are as a group. Only after a lengthy process of growth and development has the group arrived at the brink of answering the question "How can we help students become knowledge makers?" We now understand that the knowledge making process is not only discipline-based or intellectual, but involves the psychological, emotional, and intellectual dimensions of all members of the community.

\section{CONCLUSIONS}

In looking back on the process, we discovered that we had learned five lessons, both about the process of Collaborative Inquiry and about our relationship to students.

\section{Communication that is reflective offers a necessary alternative to both linear} and circular thinking. While our efforts at Collaborative Inquiry were initially circular and frustrating, we did find a way to move forward in a kind of spiralreflecting on the experience while structuring new experiences. Learning does not follow a linear path, but is often fraught with emotional impasse that is triggered 


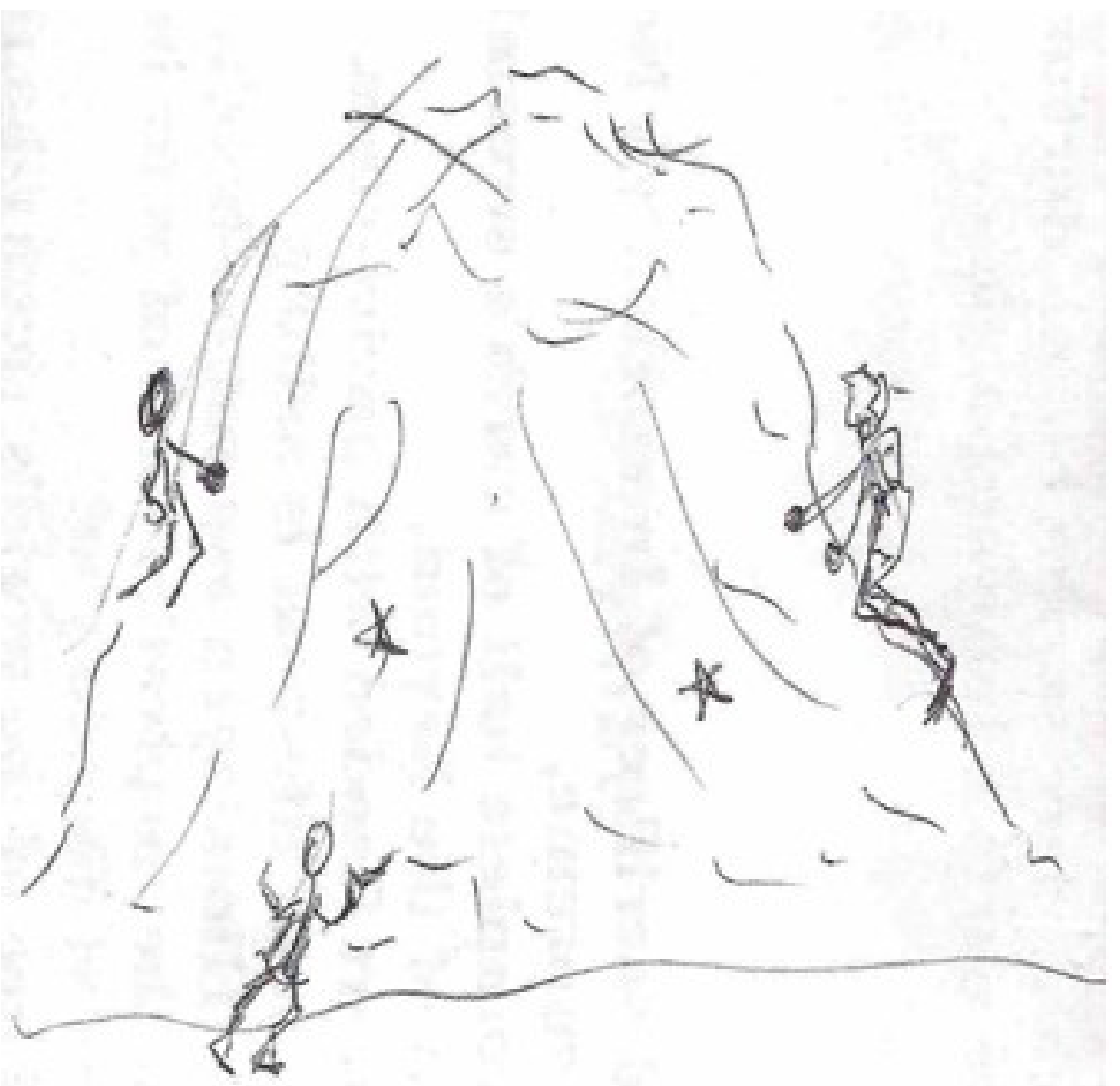

Figure 1. One participant's sketch of the group Cl process as looking for needles in a haystack

by the threats to our existing belief systems. Inquiry is the process whereby we begin to examine those assumptions and open ourselves to revision. At the heart of Collaborative Inquiry is the group interaction and communication that is key in the co-construction of knowledge. It is through this dynamic interactive giveand-take that we peel away the affective filters that often obscure the 'truths' that we seek.

2. Collaborative Inquiry requires the ability to manage conflict. When we were asked to draw our experience of CI, one us drew a picture of looking for a needle in a haystack (see Figure 1). She extended the metaphor by depicting the needle and hay as sharp; it wasn't just that the process felt futile at times, but that the process was consistently painful. Even in later stages, we had to check in with each other regarding frustrations and slights. Only by having a high tolerance for interpersonal discord were we able to work and grow.

\section{Collaborators need to find personal meaning in engaging in a Collaborative} Inquiry situation. In a classroom setting, collaboration can be imposed through the structure of the assignments, but finding personal meaning increases commit- 
ment and thereby greater accountability. We were unable to "make meaning" until we had a personal stake; the same is true for our students. The notion of teaching and learning as becoming knowledge makers creates a certain tension between a more traditional pedagogical approach in higher education in which the students are tabula rasa waiting to be written on by the experienced and knowledgeable professor and the more contemporary Vygotskyan (1978) approach to teaching learning; that learning is a dynamic interactive process through which knowledge is co-constructed. It is incumbent on us as professors in a community college setting to provide information to our students and to present and interpret the content in our respective disciplines. This task is often challenging, given the level of academic preparation of many of the students we serve. At the same time, the classroom has to provide the opportunity for interaction through which students make knowledge of that content. It is a daunting task to balance class time between the presentation of content and active dynamic application of that content. Our insights into our own processes as knowledge makers, however, confirmed the value of a Collaborative Inquiry to foster personal meaning essential in knowledge making. Those who found personal meaning in the inquiry remained as dynamic members of the collaboration; those who did not find the process meaningful at a personal level abandoned the query.

4. We exhibit almost all of the negative behaviors that we attribute to our students. As we defined our query, structured our collaboration, and navigated the quest, we found that we exhibited some of the same tendencies, behaviors, and attitudes that we typically assign to students in our classes. As one member reflected,

For almost the first year of our inquiry, I kept waiting to be told what to do. I expected our facilitator to tell us what CI is and how to do it; this sounds exactly like our complaint about our students. Our idea of our goals for our students often misses that they are people like us. I only took responsibility for my own learning and the group's learning after a distressing interaction that spurred us into action.

It was our shared experience that many students want to know what they need to know for the test but do not seem engaged in making meaning of the content.

\section{Our initial question highlights a certain (unresolvable?) tension between} our values as educators and the values of our students. Our students are makers of knowledge. They have decided to come to college, they buy cell phones and technology, many of them raise children, and many of them have commitments that dwarf our own personal responsibilities. What we want is for them to become makers of a very specific kind of knowledge. To a large extent, we're asking our student to value peer review and editorial gatekeeping, rather than crowdsourcing. When we ask them to value peer review and editorial gatekeeping as the standards of proof on which to build knowledge, we are asking them to make knowledge in new ways.

\section{REFLECTIONS}

At one of our last meetings, we considered whether any of us would attempt Collaborative Inquiry again. With a sense of the emotional investment and work, would we feel 
comfortable trying to bring it to our departments? The answers were mixed. As Coryell (2013) stated, "Learning about new ways of understanding is rarely easy or comfortable" (p. 309). Some of us found the process too painful to try to repeat; the vulnerability was overwhelming. Others said that it was worth the discomfort to learn and develop and grow. One of us reflected on her initial, almost utopian, ideal of what CI would be like:

I believed that Collaborative Inquiry presented itself as the vehicle for personal transformation. In this forum, we would be free to express ourselves in all our strengths and weaknesses, and we would be accepted, regardless. We would be able to use the synergy of the group to generate ideas and to explore possibilities. We would become fast friends and develop deep rich relationships with the other participants.

The CI process gave us a heightened self-awareness, so that we could see the emotional and personal barriers that had prevented us from solving the problems that were visible at an intellectual level. As we began to alter our perceptions through increased scrutiny, we began to alter our practices. We were discomforted by the heightened awareness to different degrees. In our final analyses, the word "vulnerable" came up over and over again.

Ultimately, we all agreed that CI increased our humility in approaching our colleagues and students. The difficulty of the process reminded us that students find knowledge making as difficult and uncomfortable as we do-even though the CI structure is not one we would use for students in our classes. The experience of not having answers in advance is always frustrating, and the search is often unavoidably painful. CI reminded us to help ourselves and our students to see the light at the end of the tunnel; it is never the light that was expected, but it is light nevertheless.

Lane Glisson is a Faculty Librarian at the Borough of Manhattan Community College, and Library Liaison to the English and Music \& Art Departments.

Shane McConnell is a Lecturer in the Developmental Skills Department at the Borough of Manhattan Community College.

Mahatapa Palit is an Associate Professor at Borough of Manhattan Community College in the Business Management Department, where she teaches Entrepreneurship and Marketing.

Jason Schneiderman is an Assistant Professor in the English Department at the Borough of Manhattan Community College; he is the author of two books of poems.

Cynthia Wiseman is an Assistant Professor in the Developmental Skills Department at the Borough of Manhattan Community College; she also teaches linguistics and critical thinking.

Lyle Yorks is Associate Professor in the Adult Learning and Leadership Program and Director of the Adult Education Guided Study Doctoral Program at Teachers College, Columbia University.

\section{REFERENCES}

Bray, J., Lee, J., Smith, L.L., \& Yorks, L. (2000). Collaborative inquiry in practice: Action, reflection, and making meaning. Thousand Oaks, CA: Sage Publications.

Brookfield, S. D. (1980). The nature of independent adult learning. Continuing Education, 3. 
Coghlan, D., \& Brannick, T. (2005). Doing action research in your own organization (2nd ed.). London: Sage.

Coryell, J. E. (2013). Collaborative, comparative inquiry and transformative cross-cultural adult learning and teaching: A western education metanarrative and inspiring a global vision. Adult Education Quarterly. 63(4), 299-320.

Greenwood, D., \& Levin, M. (2007). Introduction to action research: Social science for social change (2nd. ed.). London: Sage.

Heron, J. (1996). Co-operative inquiry: Research into the human condition. London: Sage Publications.

Heron, J., \& Reason, P. (2001) The practice of co-operative inquiry: Research "with" rather than "on" people. In P. Reason \& H. Bradbury (Eds.), Handbook of Action Research: Participative Inquiry and Practice (pp. 179 - 189). London: Sage.

Heron, J., \& Reason, P. (2008). Extending epistemology within a co-operative inquiry. In P. Reason \& H. Bradbury (Eds.), The Sage handbook of action research: Participative inquiry and practice (2nd ed.) (pp. 366-380). London: Sage.

Kasl., E., \& Yorks, L. (2012). Learning to be what we know: The pivotal role of presentational knowing in transformative learning. In E. W. Taylor \& P. Cranton (Eds.), Handbook of transformative education (pp. 503-519). San Francisco: Jossey-Bass.

Kovari, V., Hicks, R.T., Ferlazzo, L., McGarvey, G., Ochs, M., Alcántara, L., \& Yorks, L. (2005). Don't just do something, sit there: Helping others become more strategic, conceptual and creative: A cooperative inquiry. Retrieved from http://www.nyu.edu/wagner/leadership/reports /files/ LeadersLearnersGuide.pdf.

Mankey, R. (2007). Understanding holistic leadership: A collaborative inquiry. (Unpublished doctoral dissertation). Teachers College, Columbia University, NY, NY.

Mezirow, J. (1991). Transformative dimensions of adult learning. San Francisco: Jossey-Bass.

Reason, P. (1988). Human inquiry in action: Developments in new paradigm research. London: Sage.

Reason, P. (1992). Comments made during a meeting with doctoral students at Teachers College. Columbia University, New York.

Reason, P., \& Bradbury, H. (eds.). (2008). The SAGE handbook of action research: Participative inquiry and practice ( $2^{\text {nd }}$ ed.). Los Angeles, CA: Sage.

Torbert, W.R., \& Taylor S.S. (2008). Action Inquiry: Interweaving multiple qualities of attention for timely action. In P. Reason \& H. Bradbury (Eds.), Handbook of action research: Participative inquiry and practice (pp. 239-252). London: Sage Publications.

Vygotsky, L. (1978). Mind in society. London: Harvard University Press.

Yorks, L., \& Kasl, E. (2002). Toward a theory and practice for whole-person learning: Reconceptualizing experience and the role of affect. Adult Education Quarterly 52(3), 176-192.

Yorks, L., \& Kasl, E. (2006). I know more than I can say: A taxonomy for using expressive ways of knowing to foster transformative learning. Journal of Transformative Learning. 4(1), 43-64. 